\section{Closed Pores in Synthetic Graphite}

IT is well known that the bulk density of a synthetic graphite is much lower than the density of the crystallites obtained from X-ray measurement: 25-30 per cent of the volume must be empty pore space. By measurement of the real density with three different fluids, we have shown that about 20 per cent of the total pore space cannot be reached by a liquid or gas unless the graphite is reduced to a very fine particle-size, or part of the structure is removed by oxidation.

The synthetic graphites studied were pure grades (99.9 per cent carbon), prepared in a commercial graphitizing furnace, having a bulk density of 1-6 $\mathrm{gm} . / \mathrm{cm}^{3}$. The displacing fluids used for density measurements were methanol, $n$-hexane and helium. The liquid densities were measured after prolonged refluxing in the liquid used. The standard densitybottle method was used for specimens $6 \mathrm{~mm}$. or less in diameter, and larger specimens were weighed in air and in liquid. The densities of helium were measured after outgassing at $300^{\circ} \mathrm{C}$. to a pressure of $10^{-4} \mathrm{~mm}$. of mercury or less ; no measurements were taken until two hours after admitting helium, and measurable drifts with time were seldom recorded after that period. The results are considered accurate to \pm 0.3 per cent.

In all cases where they were directly compared, the liquid and helium densities agreed closely. For example, the density of a cylinder (15 mm. diameter) of synthetic graphite was measured as $2.091 \mathrm{gm} . / \mathrm{cm} .^{3}$ in $n$-hexane and as $2.093 \mathrm{gm} . / \mathrm{cm}^{3}$ in helium after pumping off the hexane; the density of an oxidized dust was $2 \cdot 224$ and $2 \cdot 220 \mathrm{gm} . / \mathrm{cm}^{3}$ in methanol and helium respectively. There was no evidence of a molecular sieve effect, as has been reported for some cokes $^{1}$, that is, the measured density was independent of the molecular size of the displacing fluid.

The density of pure flakes of natural Ceylon graphite $(99.5$ per cent carbon) was measured as $2.253 \mathrm{gm} . / \mathrm{cm}^{3}$ in methanol and $2.251 \mathrm{gm} . / \mathrm{cm}^{3}$ in helium; these values amount to $99 \cdot 3$ per cent of the value derived from $\mathrm{X}$-ray crystallographic data, which is ${ }^{2,3} 2 \cdot 266 \mathrm{gm} . / \mathrm{cm} .^{3}$. In contrest to this, the densities of specimens of the synthetic graphite were always lower than $2.21 \mathrm{gm} . / \mathrm{cm} .^{3}$. The densities of bulk specimens, that is, cylinders and plates, varied from 2.06 to $2.13 \mathrm{gm} . / \mathrm{cm}^{3}$ with no systematic variation with specimen size or with the original position of the specimen in the large manufactured block. The densities of dusts (particle diameter less than $0.4 \mathrm{~mm}$.) milled from the same blocks as provided the bulk specimens were uniformly higher, ranging from $2 \cdot 15$ to $2 \cdot 21 \mathrm{gm} . / \mathrm{cm}^{3}$, and these densities showed a tendency to increase as the particlesize of the dust decreased. For one dust examined, the sieve fraction $-36+72$ B.S.S. had a density of $2 \cdot 154 \mathrm{gm} . / \mathrm{cm}^{3}$, whereas the density of the fraction passing a 240 B.S. sieve was $2.19 \mathrm{l} \mathrm{gm} . / \mathrm{cm} .^{3}$.

Thus all measured density values found for artificial graphite were $2-8.5$ per cent lower than the experimentally determined value for natural graphite. The calculated X-ray density of a synthetic graphite comparable to that used by us (sample $A$ l, ref. 3) was only 0.2 per cent lower than the X-ray density of Ceylon graphite. The low observed densities therefore suggest the presence of inaccessible pore space in the micro-structure of synthetic graphite, formed either by the disordered stacking of the graphite erystallites or by intercrystalline linkages of non- graphitic carbon. Some of the blockages in the pores must be fairly far apart, since reducing the particle size to 70 microns opens up an appreciable fraction of the closed space.

The densities of some bulk and dust samples were re-measured after oxidation at $430^{\circ}-500^{\circ} \mathrm{C}$. in an air stream. The density always increased on oxidation, the increase being normally greater the larger the loss of weight. The density increase was most marked in the initial stages of the oxidation-- the density of a 14-mm. diameter cylinder increased from $2 \cdot 130$ to $2.194 \mathrm{gm} . / \mathrm{cm}^{3}$ on oxidation to 0.55 per cent loss of weight, and to $2 \cdot 226 \mathrm{gm} . / \mathrm{cm}^{3}$ on oxidation to 2.7 per cent loss of weight. It is suggested that slight oxidation may remove the pore blockages, either by first removing poorly crystallized material, or by oxidation occurring first at the edges and corners of crystals, and closed spaces may thus become accessible to the measuring fluid.

The significance of these results will be more fully discussed in conjunction with parallel adsorption measurements to be reported elsewhere. We wish to acknowledge experimental assistance afforded by Mr. E. A. Harper and Mr. H. Small, of this Establishment.

E. M. DResel

L. E. J. RoBERTS

Atomic Energy Research Establishment,

Harwell,

Didcot, Berks.

July 25.

1 Franklin, R, E., Trans. Farad. Soc., 45, 668 (1949).

${ }^{2}$ Nelson, J. B., and Riley, D. P., Proc. Phys. Soc., 57, 477 (1945).

3 Bacon, G. E., Acta Cryst., 3, 137 (1950).

\section{Morphology of Crystalline Synthetic Polymers}

IN a previous communication ${ }^{1}$, it has been reported that when polyethylene terephthalate crystallizes, it forms spherulites, which consist of radiating helically wound ribbons, and that other synthetic polymers behave similarly. The present communication describes effects observed with polyethylene and polyamides.

In order to observe the phenomena to be described, polyethylene and polyamide (nylon) melts were crystallized in thin layers between cover-glasses at a constant temperature within $20^{\circ} \mathrm{C}$. of the softening point. Between crossed Nicols, spherulites were seen which, in addition to the usual black cross, showed a system of concentric extinction rings, and in some cases also the beginning of a zig-zag distortion of the crosses. With decreasing temperature of crystallization, the extinction rings become gradually narrower and more closely spaced, until they can no longer be resolved with the optical microscope. The sign of birefringence of the polyethylene spherulites was negative, and that of the polyamides nearly always positive; by this it is meant that, regarding the spherulite as uniaxial, in the first case the major refractive index lies tangentially and in the second radially with respect to the spherulite. In very rare instances isolated negative polyamide spherulites have been seen, but the conditions for producing these are not known. All these effects can be explained by the morphology proposed in ref. 1. Accordingly, the above observations correspond to cases in which the radiating needles aro closely coiled helices (helical angle only a few degreos), and the increasing separa- 